\section{Comparative Clinical Study Using Short and Conventional Implants in Bilateral Jaw Posteriors}

\author{
Carlos Henrique Sardenberg Pereira ${ }^{10}$, Anna Carolina Britto de Macedo
}

Sardenberg Pereira ${ }^{2}$, Carlos Eduardo Francischone ${ }^{3}$ (D)
'School of Dentistry, Division of Periodontics, UNIG - Universidade lguaçu, Nova lguaçu, RJ, Brazil ${ }^{2}$ Department of Periodontics - Odontoclínica Central do Exército, Exército Brasileiro, Rio de Janeiro, RJ, Brazil ${ }^{3}$ Department of Dental Implants, Faculdade São Leopoldo Mandic, Campinas, SP, Brazil

Correspondence: Carlos Henrique Sardenberg Pereira, Rua Conde de Bonfim 232/908, 20520054 Rio de Janeiro, RJ, Brasil. Tel: +55-21-3234-4093. e-mail: carlossardenberg@gmail.com
The aim of this study was to clinically and radiographically compare extra short and standards implants. Forty-two implants were installed in 10 selected patients. They received prosthetic loading only after the conventional waiting time for osseointegration and the prostheses were made ferulized. Radiographic shots were performed to evaluate vertical and horizontal bone losses at times T1 (prosthetic installation), T2 (6 months follow-up) and T3 (12 months follow-up). Biological parameters such as bone level around the implants (CBL) were evaluated, $\mathrm{CBL}$ alteration (CBLC), total crown length (TCL) and implant/crown ratio (ICR) were digitally calculated. All implants included in the study were submitted to the analysis of the implant stability quotient (ISO) at the time of implant installation (TO) and at 12 months of prosthetic function (T3). Data were statistically tested. The ICR was higher in the test group than in the control group $(p<0.0001)$. The CBL measurements at the beginning of the study were $0.21 \pm 0.19 \mathrm{~mm}$ and $0.32 \pm 0.38 \mathrm{~mm}$ and at 12 months $0.65 \pm 0.24 \mathrm{~mm}$ and $0.87 \pm 0.34 \mathrm{~mm}$, respectively in the test and control groups. CBLCs and CBL were similar at all times ( $p>0.05$ ). No correlation was found between CBLC and ICR parameters, as well as between ISO and implant length. We may conclude that standards and extra short implants can provide similar clinical results in prosthetic rehabilitation of the atrophic jaw over 12 months of follow-up.
Key Words: extra short implants, oral rehabilitation, dental implants, implant prosthesis.

\section{Introduction}

One or more absences in the posterior mandible is a common defect found in clinical practice. The posterior regions of the jaws offer anatomical limitations that hinder or even prevent the rehabilitation treatment with conventional dental implants due to the lack of sufficient bone height for their placement. These limitations arise mainly from the positioning of the mandibular canal, mental foramen and maxillary sinus.

To provide height and width of bone tissue, reconstructive surgical techniques or preparatory surgeries were developed. The techniques of bone grafting, maxillary sinus lifting, osteogenic distraction and deviation of the mandibular canal are the best known. In general, these techniques increase the final cost of treatment, prolong the total time for rehabilitation, represent at least one more surgical stage, increasing patient morbidity. A systematic review showed that complications of inferior alveolar nerve reposition technique for simultaneous implantbased rehabilitation reached permanent damage in 3.4\% and $22.1 \%$ of transitory damage and the failure rate of the implant was $11 \%$ in 3 years (1). In addition, the use of bone grafts often leads to a large amount of resorption, thus favoring the increased failure rate in dental implant treatment (2). Recently, placement of short and extra short implants is considered an alternative treatment to avoid complex surgical procedures.

Authors describe that 4 to $6 \mathrm{~mm}$ length implants are defined as extra short implants, 6 to $8 \mathrm{~mm}$ length implants are defined as short implants and higher of $8 \mathrm{~mm}$ length implants are defined as standard implants $(3,4)$. With advances in surface treatment technology and structural changes in the surface of dental implants, short and extra short implants have achieved a high success rate in recent studies. The survival rate of single crowns over implantation in the posterior region showed no significant differences between the group of extra short implants and the group of standard implants. Some randomized clinical trials do not report a significant difference between extra short implants and standard implants $(>8 \mathrm{~mm})$ in the posterior region of the jaw $(3,4)$. A retrospective study reported that the 5-year survival rate for extra short implants was $98.7 \%$ and the 10 -year survival rate was $98.3 \%$, which indicated that extra short implants had a reliable long-term effect (4).

Extra short implants may provide optimal solutions in prosthetic treatment of jaws with significant bone loss. Therefore, the aim of this study was to demonstrate the results of platform switching and external prosthetic platform implants with a length of $5.5 \mathrm{~mm}$ in the posterior region of the jaw and to compare the short-term results with $8.5 \mathrm{~mm}$ length implants. 


\section{Material and Methods}

\section{Patient Selection}

We included 10 non-smoking systemically healthy patients (age range: 38-70 years; 4 men, 6 women) with the main complaint of impaired masticatory function. The inclusion criteria were as follows: no systemic disease, over 21 years of age, absence of at least two teeth in the posterior region of the bilateral mandible with residual bone height in the mandible of at least $6 \mathrm{~mm}$ wide and $10 \mathrm{~mm}$ in length and soft tissue thickness $\geq 2 \mathrm{~mm}$, natural teeth or fixed partial prosthesis in the opposing mandibles of the edentulous area and with disposition for placement of dental implants. The exclusion criteria were: being a smoker, using medication that may interfere with bone metabolism or healing, severe systemic diseases, local conditions that may compromise treatment success (ex: uncontrolled periodontal disease) and non-collaborating patients.

All treatment options, including removable or fixed partial dentures, along with their advantages and disadvantages, were clearly explained to all patients. The study protocol was in full compliance with ethical principles, including the World Medical Association's Declaration of Helsinki, revised in 2008, and was approved by the Ethics Committee of the Faculdade São Leopoldo Mandic (No: 2.813.590). All patients signed an informed consent form prior to enrolling in the study.

The treatment protocol was performed so that all 10 patients received at least 2 adjacent extra short $4.1 \mathrm{~mm} \mathrm{x}$ $5.5 \mathrm{~mm}$ (Kort HEX, Dérig, Barueri, SP, Brazil) implants in one hemi-arch and the other received at least 2 long adjacent implants $4.1 \mathrm{~mm} \times 8.5 \mathrm{~mm}$ (Biodent HEX, Dérig, Barueri, $\mathrm{SP}$, Brazi) at the posterior mandible edge, being drawn at the time of surgery which side would receive the extra


Figure 1. A) extra short implant $4.1 \mathrm{~mm}$ x $5.5 \mathrm{~mm}$ (Kort HEX, Dérig, Barueri, SP, Brazil); B): standard implant $4.1 \mathrm{~mm}$ x $8.5 \mathrm{~mm}$ (Biodent HEX, Dérig, Barueri, SP, Brazil). short implants and which side would receive the standard implants (Fig. 1).

\section{Surgical and Prosthetic Procedures}

Implant surgery was performed using the standard protocol of the Dérig implant system (Barueri, SP, Brazil). The surgical site was locally anesthetized with $2 \%$ lidocaine including 1:100 000 epinephrine. A mid-crestal incision was prepared along the edentulous ridge using $15 \mathrm{c}$ blades (Swann-Morton Ltd., Sheffield, UK). A full thickness flap was then raised to expose the alveolar bone and a surgical stent was used to mark the osteotomy area. The surgical steps were in line with the manufacturer's instructions. The implants were placed submucosally with the platform at bone level. After the cover plug was placed into the well of the implants, primary wound closure was achieved using a non-absorbable suture material. After a healing period of 12 weeks, the second stage surgery was performed and a healing abutment was placed.

Two weeks after second stage surgery, an implant level impression was made to fabricate the crown over the implants. Prosthetic rehabilitation was performed with metal-ceramic crowns, made on the implants using calcinable cylinders always joined with the adjacent implants (Fig. 2). The placement of the definitive prosthesis took place two weeks after casting with a torque of 32 $\mathrm{Ncm}$ of screwed splinted metal-ceramic crowns, the same protocol was used for both extra short and standard implants in all patients.

Patients were re-evaluated every 6 months after the placement of prostheses on implants and periodontal parameters, including probing depth (PD) and clinical insertion level (CAL) (only of natural teeth), visible plaque index (FMPS) and gingival bleeding index (FMBS) were

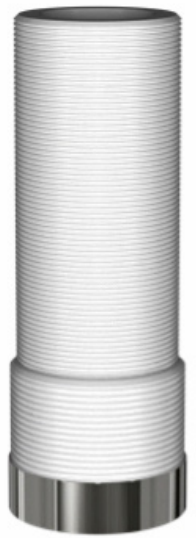

Figure 2. Showing calcinable cylinder used for making implant prostheses. 
measured and dental, periodontal, prosthetic and implant health were evaluated clinically, radiographically and with the aid of Ostell.

All surgical and prosthetic procedures and the measurement of the studied parameters were performed by the same operator.

\section{Radiographic Evaluation}

Radiographic measurements were taken immediately after the final prosthetic stage (T1) and at the reassessment periods of 6 (T2) and 12 months (T3) after implant prostheses were installed to assess the dimensional bone changes around the implants. Changes in bone level around the implants were measured on standardized periapical radiographs. To standardize the radiographs, a phosphor plate (Sorodex, Helsinki, Finland) was used with a phosphor plate holder (Endo-Bite, Kerr, Orange, CA, USA) and all radiographs were obtained by the same examiner using the long-cone parallelism technique with standard exposure times ( $60 \mathrm{kV}, 7 \mathrm{~mA}, 0.125 \mathrm{~s})$. The radiographs were stored as digital images and, in each image, the implant length (IL), implant diameter (ID), implant-prosthesis interface (IPI), relative crown length $(\mathrm{RCL})$ and the first bone-implant contact point (fBIC) were evaluated (Fig. 3). Images were exported to a java-based image analysis program (ImageJ for Windows, National Institutes of Health, Bethesda, MD), the length and diameter of each implant were used for calibration and transformation of pixels into millimeter units. The reproducibility of the measurements was validated as previously described by another author (5) and considered as "very good" due to the strength of agreement between consecutive measurements (Cohen's Kappa 0.92). All measurements were performed by the same examiner.

The reference points for bone level measurements around the implants (CBL) were the IPI level and the $\mathrm{ABIC}$, both in the mesial and distal aspects. After recording measurements independently on both sides, CBL change (CBLC) was calculated by subtracting consecutive followup measurements (ie, CBL at $\mathrm{T} 2-\mathrm{CBL}$ at $\mathrm{T} 1=\mathrm{CBLC}$ at 6 months). The total crown length (TCL) was calculated as 1 $\mathrm{mm}$ longer (porcelain space) than the $\mathrm{RCL}$, and the implant/ crown ratio (ICR) was calculated as IL/TCL.

\section{Evaluation with Ostell:}

All implants included in the study will be submitted to the analysis of the implant stability quotient (ISO), through the resonance frequency with the Osstell Mentor device (Integration Diagnostics AB, Göteborg, Sweden). Measurements were performed at the time of implant installation (TO) and at 12 months of prosthetic function (T3).

\section{Statistical Analysis:}

A statistical program (GraphPad Prism version 8.0.0 for Mac OS X, GraphPad Software, La Jolla, CA) was used for statistical analysis and graph preparation. The implant was selected as the unit of statistical analysis. The distribution of variables was validated by the D'Agostino-Pearson normality test. Intergroup differences in patient age, implant diameter and length, CBL, CBLC, TCL, TCL/IL were assessed using the unpaired t-test. Intragroup differences in CBL and ISO were evaluated using the one-way ANOVA test of repeated measurements and the Holm-Sidak multiple comparison test, with individual variations calculated for each comparison. The gender and number of implants in the molar and premolar region were compared by the chisquare test. Correlations between changes in IL, ID, TCL, ICR and $\mathrm{CBL}$ were evaluated by Pearson's correlation test. All

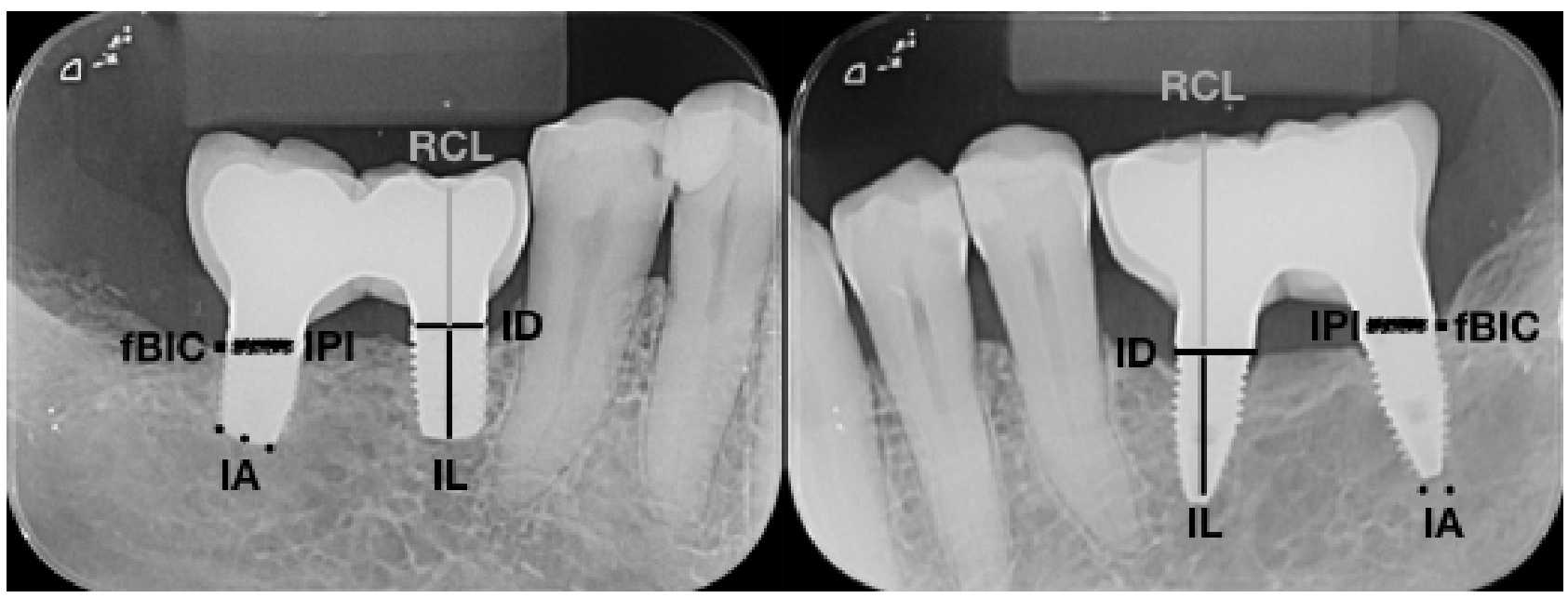

Figure 3. ID: implant diameter, IL: implant length, AI: apex implant, IPI: implant prosthesis interface, RCL: relative crown length, fBIC: first bone-to-implant contact 
statistical tests were performed at the significance level $a=0.05$. The 12 month data are included in the statistical analyzes.

\section{Results}

A total of 42 implants were installed, 21 implants in the test group (Extra Short Implant) and 21 implants in the control group (Standard Implant) were followed for 12 months and no biological complications were observed during this period. The implants were positioned in molar or pre-molar region on posterior mandible were nine patients received 2 implants in each side and one patient received 3 implants in each side. The metalloceramic crowns of two patients in the test group had their screws loosened and were properly retightened. The average measures of pocket depth and clinical insertion level were $<2 \mathrm{~mm}$ and the visible plaque and bleeding on probing were $15 \%$ at all times of the evaluation.

Demographic parameters, implant specifications and site characteristics are shown in Table 1. Patient characteristics and implant location were similar in the studied groups ( $p>0.005$ ). TCL and ICR were significantly higher in the test group compared to the control group $(p<0.0001)$.

At the beginning of the study, the CBL for the test and control groups was $0.21 \pm 0.19 \mathrm{~mm}$ and $0.32 \pm 0.38 \mathrm{~mm}$, at 6 months it was $0.62 \pm 0.26 \mathrm{~mm}$ and $0.88 \pm 0.42 \mathrm{~mm}$ and at

Table 1. Demographic variables, implant specifications and site characteristics at $\mathrm{T} 1$

\begin{tabular}{lcc}
\hline Parameters & Test group $\mathrm{n}=21$ & Control Group $\mathrm{n}=21$ \\
\hline Age & $52.77 \pm 7.15$ & $52.77 \pm 7.15$ \\
Man|Woman (n) & $4 \backslash 6$ & $4 \mid 6$ \\
Premolar|Molar (n) & $9 \backslash 12$ & $10 \backslash 11$ \\
CBL (mm) & $0.21 \pm 0.19$ & $0.32 \pm 0.38$ \\
TCL (mm) & $13.41 \pm 1.4$ & $12.93 \pm 1.96$ \\
ICR & $2.77 \pm 0.48^{*}$ & $1.52 \pm 0.28$ \\
\hline
\end{tabular}

*Significant difference compared to control group ( $\mathrm{p}<0.0001)$. CBL: crestal bone level, TCL: total crown length, ICR: implant/crown ratio. All data are presented as average \pm standard deviation (SD).

Table 2. Evaluation of crestal bone level (CBL) in mm according to the studied groups (averages \pm SD)

\begin{tabular}{lcc}
\hline CBL & Test group $\mathrm{n}=21$ & Control Group $\mathrm{n}=21$ \\
\hline T1 & $0.21 \pm 0.19$ & $0.32 \pm 0.38$ \\
T2 (6 months) & $0.62 \pm 0.26$ & $0.88 \pm 0.42$ \\
T3 (12 months) & $0.65 \pm 0.24$ & $0.87 \pm 0.34$ \\
\hline
\end{tabular}

12 months $0.65 \pm 0.24 \mathrm{~mm}$ and $0.87 \pm 0.34 \mathrm{~mm}$, respectively. CBLs at $\mathrm{T} 1$ and $\mathrm{T} 2$ were similar in the studied groups, but at 12 months was significantly higher in the control group ( $p=0.04)$. No statistically significant difference was detected in $C B L$ values in the intragroup comparisons between the evaluated moments ( $p>0.05$ ) (Table 2).

CBLCs between T1-T2 were $0.41 \pm 0.27 \mathrm{~mm}$ and $0.56 \pm 0.23$ $\mathrm{mm}$ in the test and control group and between T1-T3 with $0.44 \pm 0.17 \mathrm{~mm}$ and $0.59 \pm 0.24 \mathrm{~mm}$, respectively, there were no statistically significant differences between groups ( $p>0.05$ ). Similarly, CBLCs between T2-T3 were $0.03 \pm 0.16$ $\mathrm{mm}$ and $-0.01 \pm 0.19 \mathrm{~mm}$ for the test and control groups, respectively, with no statistically significant difference between the groups ( $p>0.05$ ). Intragroup CBLCs between T1-T2, T1-T3 and T2-T3 were not statistically significant ( $>0.05$ ) (Table 3).

On the day of implant installation, the ISO for the test and control groups was $72.87 \pm 4.33$ and $69.24 \pm 4.09$ and at 12 months $74.60 \pm 3.33$ and $72.44 \pm 2,34$, respectively. No statistically significant difference was detected in ISO values in the intragroup comparisons between the evaluated moments $(p>0.05)$ (Table 4).

\section{Discussion}

This study compares and tracks extra short implants of external hexagon connection with standard length implants in both hemi-arch for 12 months. All $5.5 \mathrm{~mm}$ implants were restored with ferulized (united) total crowns, as described in the previous studies $(6,7)$. Rehabilitation of the atrophic mandible using 4-mm-long implants had already been reported previously $(8,9)$, and also, unlike previous studies that compared extra short and standard implants (9-12), the present study is the first report of 5.5-mm-long bone implants compared with standard implants installed each on one side of the same arch using external hexagon connection implants.

All patients followed the study protocol and, during the entire observation period, there was no withdrawal or loss of any implant, which resulted in 100\% survival in both groups. This result is compatible with randomized clinical trials and controlled clinical trials, which report success rates of 97 to $100 \%$ with follow-up periods of 8 to 36 months (9-13).

Table 3. Evaluation of crestal bone level (CBL) variation in $\mathrm{mm}$ according to the studied groups (averages $\pm \mathrm{SD}$ ) in the described periods

\begin{tabular}{lcc}
\hline CBLC & Test group $\mathrm{n}=21$ & Control Group $\mathrm{n}=21$ \\
\hline T1-T2 & $0.41 \pm 0.27$ & $0.56 \pm 0.23$ \\
T1-T3 & $0.44 \pm 0.17$ & $0.59 \pm 0.24$ \\
T2-T3 & $0.03 \pm 0.16$ & $-0.01 \pm 0.19$ \\
\hline
\end{tabular}


All implants in the present study were placed on native bone. If we evaluate the results of this study in conjunction with previous studies $(10,11)$, the present findings suggest that placement of an extra short implant may be appropriate when the residual bone height is less than $8 \mathrm{~mm}$ and eliminates the need for procedures of maxillary sinus elevation, lower alveolar nerve lateralization and extensive bone regeneration.

Throughout the study, the CBLC values and diameter of the implants used were similar in the studied groups, although the $\mathrm{RCl}$ was significantly different. In addition, $\mathrm{CBL}$ values at 12 months in the control group were significantly higher. The present results are in line with those reported in the recent review by Quaranta et al. (12) who proposed that the crown/implant ratio did not affect implant survival rates or CBLC. These findings may suggest that implant length, implant diameter, and crown/implant ratio may not directly affect survival rate and CBLC during the one-year follow-up period. In addition, it should be noted that the diameter of all implants was $4.1 \mathrm{~mm}$ and all of them were placed in the posterior region of the mandible and were restored as screw-retained joined prostheses, therefore, the results of the present study probably differ from those with unitary rehabilitated extra short implants.

Goiato et al. (14) compared six different designs of extra short implants and demonstrated that the stress distribution varies according to the implant shape and the screw design. In addition, the surface area of implants of similar length and diameter may differ significantly in their design (15). The extra short implants used in the present study have cylindrical body, which increase the total surface area and may also strengthen the implant against occlusal forces. Therefore, it can be speculated that the results may differ between extra short implants with different shapes and screw designs.

In a recent meta-analysis, it was concluded that implants placed at sites with thick soft tissue $(>2 \mathrm{~mm})$ have a lower CBL (16), as such, it was proposed that soft tissue thickness may affect bone loss around the dental implants and that $2 \mathrm{~mm}$ is the ideal minimum soft tissue thickness. All implants in the present study were placed at the alveolar crest level and all were at least $2 \mathrm{~mm}$ thick soft tissue at the baseline. Therefore, soft tissue thickness $>2 \mathrm{~mm}$ may have reduced CBL around implants, resulting

Table 4. ISQ evaluation with Ostell according to the groups studied (average $\pm \mathrm{SD}$ )

\begin{tabular}{ccc}
\hline ISQ & Test group $\mathrm{n}=21$ & Control Group $\mathrm{n}=21$ \\
\hline T0 (0 months) & $72.87 \pm 4.33$ & $69.24 \pm 4.09$ \\
T3 (12 months) & $74.60 \pm 3.33$ & $72.44 \pm 2.34$ \\
\hline
\end{tabular}

in a minimum of CBLC for external hexagon connection implants. Some authors believe that a sufficient band of keratinized mucosa is necessary, or at least beneficial, for the stability and function of loaded implants, the prevention of recession, and the maintenance of oral hygiene (17-19).

The lack of correlation between CBLC and prosthetic or implant-related parameters during the evaluation time may suggest that TCL and ICR in extra short and standard implants similarly affect CBLC around implants and these parameters are clinically irrelevant.

We found few studies in the literature using implants of lengths less than $6 \mathrm{~mm}$. In studies favoring the use of extra short implants smaller than $6 \mathrm{~mm}$, the presence of a characteristic common to almost all the studied systems was noticed, the cone morse implant / abutment connection $(20,21)$. These connections would have a fundamental role to reduce the incidence of mechanical complications since in treatments with short and extra short implants the ICR is unfavorable (22). However, our work showed that even extra short external connection implants can behave satisfactorily when rehabilitated using a swiching platform.

Regarding the ISO analysis, the present study did not present statistically significant difference in the evaluated periods, therefore, we found no relationship between ISO values and implant length. Perhaps, consecutive repetitive measurements over a longer period would better assess implant stability in relation to its length (23).

In conclusion, current findings suggest that $5.5 \mathrm{~mm}$ long bone level implants can be useful in the rehabilitation of the atrophic maxilla/mandible when restored with joined crowns. These implants appear to provide results similar to those obtained with standards implants during the first year after loading. Larger-scale studies with longer follow-up periods are needed to better assess survival and success rates of these very short atrophic mandible implants.

\section{Resumo}

0 objetivo deste estudo foi comparar clínica e radiograficamente implantes extra curtos e padrões. Quarenta e dois implantes foram instalados em 10 pacientes selecionados. Eles receberam carga protética somente após o tempo de espera convencional para a osseointegração e as próteses foram feitas ferulizadas. As imagens radiográficas foram realizadas para avaliar as perdas ósseas verticais e horizontais nos tempos T1 (instalação protética), T2 (6 meses de acompanhamento) e T3 (12 meses de acompanhamento). Parâmetros biológicos como nível ósseo ao redor dos implantes (CBL) foram avaliados, alteração CBL (CBLC), comprimento total da coroa (TCL) e relação implante / coroa (ICR) foram calculados digitalmente. Todos os implantes incluidos no estudo foram submetidos à análise do quociente de estabilidade do implante (ISO) no momento da instalação do implante (T0) e aos 12 meses de função protética (T3). Os dados foram testados estatisticamente. A ICR foi maior no grupo teste do que no grupo controle $(p<0,0001)$. As medidas de $C B L$ no início do estudo foram de $0,21 \pm 0,19 \mathrm{~mm}$ e 0,32 $\pm 0,38 \mathrm{~mm}$ e em 12 meses $0,65 \pm 0,24$ $\mathrm{mm}$ e $0,87 \pm 0,34 \mathrm{~mm}$, respectivamente nos grupos teste e controle. CBLCs e $C B L$ foram semelhantes em todos os momentos $(p>0,05)$. Não foi encontrada correlação entre os parâmetros CBLC e ICR, bem como entre 
o ISO e o comprimento do implante. Podemos concluir que padrões e implantes extra curtos podem fornecer resultados clínicos semelhantes na reabilitação protética da mandibula atrófica ao longo de 12 meses de acompanhamento.

\section{Acknowledgements}

The implants used in this study were kindly provided by the company Dérig, Barueri, SP, Brazil.

\section{References}

1. Palacio Garcia-Ochoa A, Pérez-González $F$, Negrillo Moreno A, Sánchez-Labrador L, Cortés-Bretón Brinkmann J, Martínez-González $J M$, et al. Complications associated with inferior alveolar nerve reposition technique for simultaneous implant-based rehabilitation of atrophic mandibles. A systematic literature review. J Stomatol Oral Maxillofac Surg. 2020, S2468-7855(19)30296-4. doi: 10.1016/j. jormas.2019.12.010. [Epub ahead of print].

2. Barone $A$, Toti $P$, Menchini-Fabris GB, Felice $P$, Marchionni S, Covani U. Early volumetric changes after vertical augmentation of the atrophic posterior mandible with interpositional block graft versus onlay bone graft: A retrospective radiological study. J Craniomaxillofac Surg 2017;45:1438-1447.

3. Jung RE, Al-Nawas B, Araujo M, Avila-Ortiz G, Barter S, Brodala N, et al. Group 1 ITI Consensus Report: The influence of implant length and design and medications on clinical and patient-reported outcomes. Clin Oral Implants Res 2018;29:69-77.

4. Shah SN, Chung J, Kim DM, Machtei EE. Can extra-short dental implants serve as alternatives to bone augmentation? A preliminary longitudinal randomized controlled clinical trial. Quintessence Int 2018:49:635-643.

5. Nizam N, Bengisu O, Sonmez S. Micro- and macrosurgical techniques in the coverage of gingival recession using connective tissue graft: 2 years follow-up. J Esthet Restor Dent 2015;27:71-83.

6. Gulje FL, Raghoebar GM, Vissink A, Meijer HJ. Single crowns in the resorbed posterior maxilla supported by either $6-\mathrm{mm}$ implants or by 11-mm implants combined with sinus floor elevation surgery: a 1-year randomised controlled trial. Eur J Oral Implantol 2014;7:247-255.

7. Nizam N, Bengisu 0, Sonmez S. Micro- and macrosurgical techniques in the coverage of gingival recession using connective tissue graft: 2 years follow-up. J Esthet Restor Dent 2015;27:71-83.

8. Quaranta A, D'Isidoro O, Bambini F, Putignano A. Potential bone to implant contact area of short versus standard implants: an in vitro micro-computed tomography analysis. Implant Dent 2016;25:97-102.

9. Ravidà A, Barootchi $S$, Askar H, Suárez-López Del Amo F, Tavelli L, Wang HL. long-term effectiveness of extra-short $(\leq 6 \mathrm{~mm})$ Dental implants: a systematic review. Int J Oral Maxillofac Implants 2019;34:68-84.

10. Pohl V, Thoma DS, Sporniak-Tutak K, Garcia-Garcia A, Taylor TD, Haas $\mathrm{R}$, et al. Short dental implants (6 $\mathrm{mm}$ ) versus long dental implants (11$15 \mathrm{~mm}$ ) in combination with sinus floor elevation procedures: 3-year results from a multicentre, randomized, controlled clinical trial. J Clin Periodontol 2017;44:438-445.
11. Thoma DS, Zeltner $\mathrm{M}$, Husler J, Hammerle $\mathrm{CH}$, Jung RE. EAO Supplement Working Group 4 - EAO CC 2015 Short implants versus sinus lifting with longer implants to restore the posterior maxilla: a systematic review. Clin Oral Implants Res 2015;11:154-169.

12. Quaranta A, Piemontese M, Rappelli G, Sammartino G, Procaccini M. Technical and biological complications related to crown to implant ratio: a systematic review. Implant Dent 2014;23:180-187.

13. Taschieri S, Lolato A, Testori T, Francetti L, Del Fabbro M. Short dental implants as compared to maxillary sinus augmentation procedure for the rehabilitation of edentulous posterior maxilla: Three-year results of a randomized clinical study. Clinical implant dentistry and related research 2018;20:9-20.

14. Goiato MC, de Medeiros RA, Sonego MV, de Lima TM, Pesqueira AA, Dos Santos DM. Stress distribution on short implants with different designs: a photoelastic analysis. J Med Eng Technol 2017;41:115-121.

15. Quaranta A, D'Isidoro O, Bambini F, Putignano A. Potential Bone to Implant Contact Area of Short Versus Standard Implants: An In Vitro Micro-Computed Tomography Analysis. Implant Dent 2016;25:97-102.

16. Suárez-López Del Amo F, Lin GH, Monje A, Galindo-Moreno P, Wang HL. Influence of soft tissue thickness on peri-implant marginal bone loss: a systematic review and meta-analysis. J Periodontol 2016;87:690-699.

17. Frisch $E$, Ratka-Krüger P. A new technique for peri-implant recession treatment: Partially epithelialized connective tissue grafts. Description of the technique and preliminary results of a case series. Clin Implant Dent Relat Res 2020 doi: 10.1111/cid.12897;10.1111/cid.12897. [Epub ahead of print].

18. Ustaoglu G, Paksoy T, Gumus KC. Titanium-prepared platelet-rich fibrin versus connective tissue graft on peri-implant soft tissue thickening and keratinized mucosa width: a randomized, controlled trial. J Oral Maxillofac Surg 2020;S0278-2391(20)30209-3. doi: 10.1016/j. joms.2020.02.019. [Epub ahead of print].

19. Sukuroglu E, Baltacioglu E. Analyses of clinical and osteoimmunological parameters on keratinized mucosa around dental implants. Niger J Clin Pract 2019;22:652-660.

20. Bordin D, Bergamo ETP, Bonfante EA, Fardin VP, Coelho PG. Influence of platform diameter in the reliability and failure mode of extra-short dental implants. J Mech Behav Biomed Mater 2018;77:470-474.

21. Pommer B, Mailath-Pokorny G, Haas R, Buseniechner D, Millesi W, Fürhauser R. Extra-short $(<7 \mathrm{~mm})$ and extra-narrow diameter $(<3.5$ $\mathrm{mm}$ ) implants: a meta-analytic literature review. Eur J Oral Implantol 2018;11:S137-S146.

22. Ravidà A, Wang IC, Barootchi S, Askar H, Tavelli L, Gargallo Albiol J, et al. Meta-analysis of randomized clinical trials comparing clinical and patient-reported outcomes between extra-short ( $\leq 6 \mathrm{~mm}$ ) and longer ( $\geq 10 \mathrm{~mm}$ ) implants. J Clin Periodontol 2019;46:118-142.

23. Sencimen M, Gulses A, Ozen J, Dergin C, Okçu KM, Ayyıldız S, Altuğ $H A$, et al. Early detection of alterations in the resonance frequency assessment of oral implant stability on various bone types: A clinical study. J Oral Implantol 2011;37:411-419.

Received December 5, 2019 Accepted June 1, 2020 